\title{
MECHANICAL PERFORMANCE OF TEXTILE REINFORCED CONCRETE CONTAINING STEEL FIBERS AND BASALT FIBERS SUBJECTED TO HIGH TEMPERATURES
}

\author{
PING XU*, YUHAO CUI*, JUNFENG DAI**, "SHUREN WANG*, MINXIA ZHANG*, ZHENGUO HOU** \\ *School of Civil Engineering, Henan Polytechnic University, Jiaozuo, Hennan, 454003, China \\ **China Construction Seventh Engineering Division Corp. Ltd., Zhengzhou, Hennan, 450004, China \\ "E-mail: shurenwang@hpu.edu.cn
}

Submitted April 21, 2021; accepted July 23, 2021

\begin{abstract}
Keywords: Textile reinforced concrete, Alumina cement, High-temperature resistance, Basalt fiber, Steel fiber
Textile reinforced concrete (TRC) was prepared from high-alumina cement mixed with short-cut basalt fiber or steel fiber for the objective to analyze the mechanical performance and deterioration mechanism at high temperature. The results show that the high-temperature resistance of TRC matrix concrete can be improved by adding steel fibers and basalt fibers, but the compressive strength of concrete decreases with the increase of temperature in a quadratic parabolic law, while the flexural strength decreases in a linear law. The addition of basalt fiber significantly improves the bending bearing capacity of the TRC plates. In comparison, the addition of steel fiber significantly improves the flexural strength of TRC thin-plates above $600{ }^{\circ} \mathrm{C}$. The scanning electron microscopy indicates that when the temperature surpasses $600{ }^{\circ} \mathrm{C}$, the addition of basalt fiber and the steel fiber surface are significantly damaged by high-temperature deterioration. The deterioration of the mechanical performance of TRC thin-plates at high temperatures is caused mainly by changes in the chemical composition of the concrete matrix, deterioration of the fiber and damage of the bonding surface. The results obtained in this study can provide the theoretical support for the design and application of TRC in a high-temperature environment.
\end{abstract}

\section{INTRODUCTION}

Textile reinforced concrete (TRC), as a new type of fiber-reinforced cement composite, is now widely used in the construction industry such as curtain wall structures, sandwich structures, reinforced and repaired shell structures and reinforced members [1-2]. Owing to its characteristics of shallow thickness, light weight, high strength and good integrity [3], TRC is used mainly on the surfaces of the structure members. This material can be severely damaged by fire; therefore, it is of great significance to study the degradation, bond failure and mechanical performance of the fiber and concrete after exposure to high temperatures.

The changes in the performance of TRC components in a high-temperature environment have been conducted in recent years. Truong et al. used direct tension experiments to study the influence of high temperature on the tensile behavior of TRC samples by using epoxy resin, aluminum oxide powder, and other methods to treat braided carbon fiber [4]. Raoof and Bournas compared the bond behaviors of TRC and fiber reinforced plastic (FRP) on concrete surfaces at high temperatures and found that the bond behavior of TRC was better than that of FRP [5]. Therefore, the addition of TRC improves the bearing behavior of concrete members at high temperatures more than that containing FRP [6-7]. However, the research on the change rule of mechanical performance has not been proved.

Sui et al. compared the bending behaviors of concrete slabs containing FRP and TRC under fire condi- tions by using the four-point bending test [8]. The results showed that reinforced hollow plates containing TRC had a higher cracking load, smaller cracking deflection, smaller peak load and larger failure deflection after exposure to high temperatures. Moreover, the high-temperature mechanical performance of cement-based materials can be improved by adding short-cut fibers [9-11] In particular, incorporating these fibers into TRC can greatly improve the strength and stiffness of the TRC components and their anti-crack performance under high temperatures [12-14]. However, further research is needed on the fiber content and damage mechanism of TRC with the increase of temperature.

High-alumina cement is more suitable for application in concrete components under high-temperature environments [15-16]. In the present study, basalt fiber and steel fiber prismatic concrete containing high-alumina cement, basalt fiber TRC and steel fiber TRC were prepared, and compressive and flexural tests of the matrix concrete, four-point bending tests of the TRC sheets, and corresponding microscopic electron microscopy scanning and X-ray diffraction analysis were carried out. The effects of incorporating different fibers on the mechanical performance, microstructure and chemical component changes of high aluminate cement TRC before and after high temperature were investigated. The experimental results explain the changing pattern of mechanical property degradation of TRC concrete after high temperature and its deterioration mechanism, which provides theoretical support for the design of TRC with high-temperature requirements. 


\section{EXPERIMENTAL}

\section{Materials}

The raw test materials include CA-50 aluminate cement, fly ash, silica fume, sand and ST-01A polycarboxylic acid water-reducing agent. The chemical composition of cement, fly ash and silica fume is shown in Table 1. Unlike ordinary concrete, the sand used in the aggregate had two different particles sizes of $0-0.6 \mathrm{~mm}$ and $0.6-1.2 \mathrm{~mm}$, respectively. To ensure good grain composition, the content of the latter size was twice that of the former. The mesh size of the basalt fiber textile was $10 \times 10 \mathrm{~mm}$, as shown in Figure 1 . Xu et al. found

Table 1. Chemical composition of cement, fly ash and silica fume.

\begin{tabular}{lrrrrr}
\hline Materials & \multicolumn{1}{c}{$\begin{array}{c}\mathrm{SiO}_{2} \\
(\%)\end{array}$} & \multicolumn{1}{c}{$\begin{array}{c}\mathrm{CaO} \\
(\%)\end{array}$} & \multicolumn{1}{c}{$\begin{array}{c}\mathrm{Al}_{2} \mathrm{O}_{3} \\
(\%)\end{array}$} & $\begin{array}{c}\mathrm{Fe}_{2} \mathrm{O}_{3} \\
(\%)\end{array}$ & $\begin{array}{c}\mathrm{MgO} \\
(\%)\end{array}$ \\
\hline CA-50 & 6.33 & 35.21 & 55.11 & 2.04 & 1.02 \\
Fly ash & 53.62 & 4.92 & 32.05 & 7.21 & 0.52 \\
Silica fume & 94.03 & 0.48 & 0.33 & 0.81 & 0.55 \\
\hline
\end{tabular}

that epoxy resin deteriorates at $100 \sim 200{ }^{\circ} \mathrm{C}$, and TRC specimens begin to crack at $300{ }^{\circ} \mathrm{C}$ [17]. Therefore, a basalt fiber network excluding adhesive treatment was used in this test. The specific parameters are shown in Table 2. The test employed $6 \mathrm{~mm}$ short-cut basalt fiber and steel fiber with diameters of $17.4 \mu \mathrm{m}$ and $0.12 \mathrm{~mm}$ and tensile strength of $\geq 2000 \mathrm{MPa}$ and $\geq 2850 \mathrm{MPa}$, respectively.

\section{Specimen preparation}

As shown in Figure 2a, the size of the specimen for the basic mechanical performance test of prismatic concrete without basalt fiber textile was $40 \times 40 \times 160 \mathrm{~mm}$. The proportion of prismatic concrete is shown in Table 3 , where $\mathrm{CA}$ represents prismatic concrete without shortcut fibers; CAB- 0.25 , CAB-0.5, CAB- 0.75 and CAB1.0 represent short-cut basalt fiber concrete matrix with volume ratios of $0.25,0.5,0.75$ and 1.0 , respectively; and CAS-0.5, CAS-1.0, CAS-1.5 and CAS-2.0 represent short-cut steel fiber concrete matrix with volume ratios of $0.5,1.0,1.5$ and 2.0 , respectively.

Table 2. Material parameters of basalt fiber textile.

\begin{tabular}{lccccc}
\hline Fiber species & $\begin{array}{c}\text { Tensile strength } \\
(\mathrm{MPa})\end{array}$ & $\begin{array}{c}\text { Elastic modulus } \\
(\mathrm{MPa})\end{array}$ & $\begin{array}{c}\text { Elongation at break } \\
(\%)\end{array}$ & $\begin{array}{c}\text { Density } \\
\left(\mathrm{g} \cdot \mathrm{cm}^{-3}\right)\end{array}$ & $\begin{array}{c}\text { Fracture strength retention } \\
\text { rate of alkali-resistant } \\
\text { monofilament } \\
(\%)\end{array}$ \\
\hline Basalt fiber textile & $\geq 1050$ & $\geq 75$ & $\leq 3.0$ & 2.7 & $\geq 75$ \\
\hline
\end{tabular}

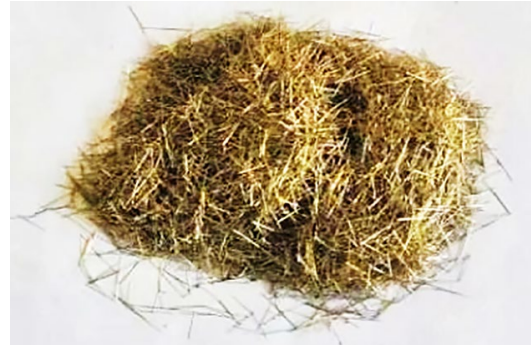

a) steel fiber

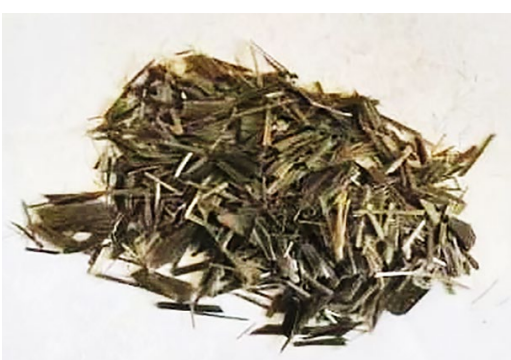

b) basalt fiber

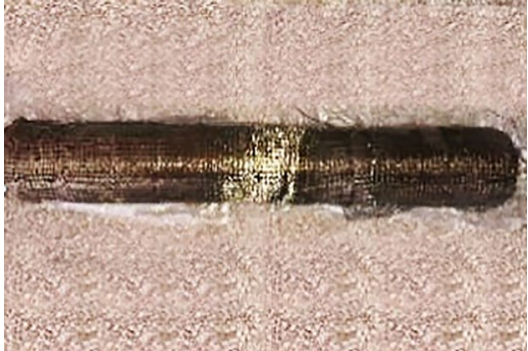

c) basalt fiber textile

Figure 1. Parameters of fibers and basalt fiber textile: a) steel fiber, b) basalt fiber, c) basalt fiber textile.

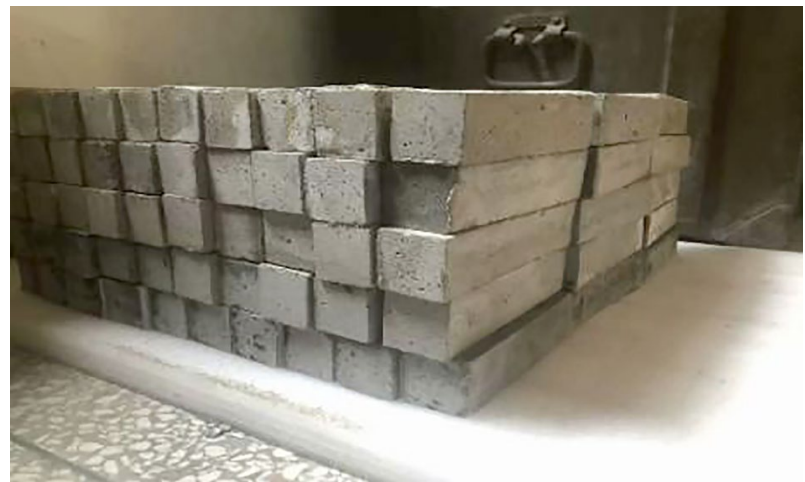

a) prism concrete test specimens

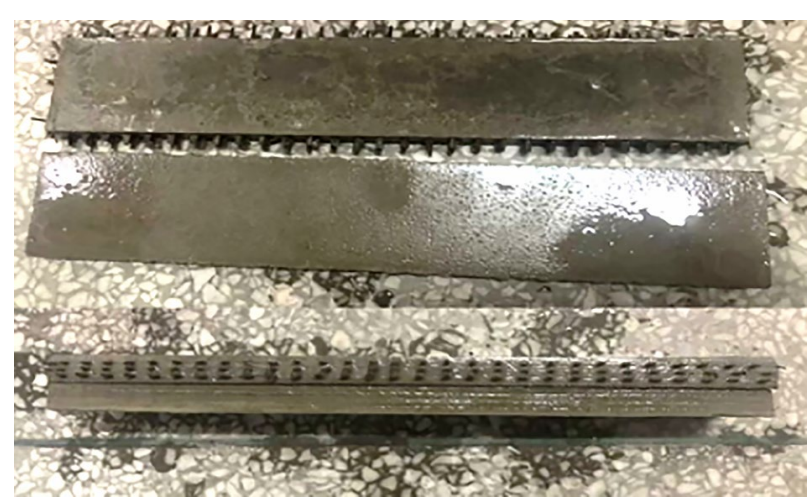

b) thin plate specimen of TRC

Figure 2. Specimen fabrication techniques: a) prism concrete test specimens, b) thin plate specimen of TRC. 
Table 3. Proportion of prism concrete $\left(\mathrm{kg} \cdot \mathrm{m}^{-3}\right)$.

\begin{tabular}{lcccccccc}
\hline Serial number & Cement & Silica fume & Fly ash & $\begin{array}{c}0-0.6 \mathrm{~mm} \\
\text { sand }\end{array}$ & $\begin{array}{c}0.6-1.2 \mathrm{~mm} \\
\text { sand }\end{array}$ & Water & $\begin{array}{c}\text { Water } \\
\text { reducer }\end{array}$ & $\begin{array}{c}\text { Fiber volume } \\
\text { percentage (\%) }\end{array}$ \\
\hline CA & 682 & 48.7 & 243.5 & 405 & 810 & 389.6 & 13.64 & - \\
CAB-0.25 & 682 & 48.7 & 243.5 & 405 & 810 & 389.6 & 13.64 & 0.25 \\
CAB-0.5 & 682 & 48.7 & 243.5 & 405 & 810 & 389.6 & 13.64 & 0.5 \\
CAB-0.75 & 682 & 48.7 & 243.5 & 405 & 810 & 389.6 & 13.64 & 0.75 \\
CAB-1.0 & 682 & 48.7 & 243.5 & 405 & 810 & 389.6 & 13.64 & 1.0 \\
CAS-0.5 & 682 & 48.7 & 243.5 & 405 & 810 & 389.6 & 13.64 & 0.5 \\
CAS-1.0 & 682 & 48.7 & 243.5 & 405 & 810 & 389.6 & 13.64 & 1.0 \\
CAS-1.5 & 682 & 48.7 & 243.5 & 405 & 810 & 389.6 & 13.64 & 1.5 \\
CAS-2.0 & 682 & 48.7 & 243.5 & 405 & 810 & 389.6 & 13.64 & 2.0 \\
\hline
\end{tabular}

As shown in Figure $2 b$, the size of the specimen for the bending test of TRC thin plate with basalt fiber textile was $280 \times 50 \times 12 \mathrm{~mm}$. The basalt fiber textile contains three layers. The upper and lower protective layers, as well as the spacing between each layer, were each $3 \mathrm{~mm}$ in thickness. The fiber content of TRC thin plate is shown in Table 4, where TCA represents TRC thin plates without short-cut fiber; TCAB-1.0 represents the short-cut basalt fiber TRC with volume ratio of 1.0, and TCAS-2.0 represents the short-cut steel fiber TRC with volume ratio of 2.0 .

Table 4. TRC sheet specimens.

\begin{tabular}{lccc}
\hline $\begin{array}{l}\text { Serial } \\
\text { number }\end{array}$ & $\begin{array}{c}\text { Volume ratio } \\
\text { of short-cut } \\
\text { basalt fiber } \\
(\%)\end{array}$ & $\begin{array}{c}\text { Volume ratio } \\
\text { of short-cut } \\
\text { steel fiber } \\
(\%)\end{array}$ & $\begin{array}{c}\text { Specimen sizes } \\
(\mathrm{mm})\end{array}$ \\
\hline TCA & - & - & $280 \times 50 \times 12$ \\
TCAB-1.0 & 1.0 & - & $280 \times 50 \times 12$ \\
TCAS-2.0 & - & 2.0 & $280 \times 50 \times 12$ \\
\hline
\end{tabular}

After the prismatic specimens and TRC thin plates are poured, they are put into a constant temperature of $20 \pm 1{ }^{\circ} \mathrm{C}$ and relative humidity of $95 \%$ or more in a curing box for 28 days.

\section{Test method}

In this experiment, the test blocks were firstly subjected to high-temperature treatment, and before being put into the high-temperature furnace (TDL-1400F, Beijing Dezhi Rongtai Environmental Protection Technology Co., Ltd. Beijing, China), the test blocks were put into the drying oven (Wujiang Wanlian Electric Heating Equipment Co., Ltd. Wujiang, China) for drying treatment. Then, the specimen was placed in a high-temperature furnace and was heated at a rate of $10{ }^{\circ} \mathrm{C} \mathrm{min}^{-1}$. After the specimen was loaded to the target temperature $\left(200,400,600\right.$ or $\left.800{ }^{\circ} \mathrm{C}\right)$, it was held at constant temperature for $60 \mathrm{~min}$. The specimen was then removed and cool naturally to room temperature before the mechanical performance was tested.

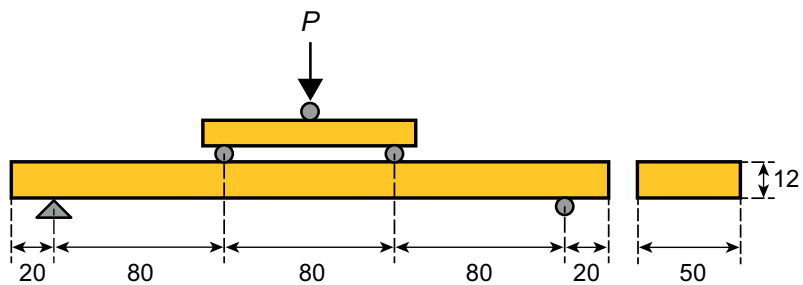

Figure 3. Four-point bending test model (mm).

After the specimens were processed at high temperatures, the flexural and compressive tests were carried out for the prismatic specimens. The loading rate of the flexural test is $50 \pm 10 \mathrm{~N} \cdot \mathrm{s}^{-1}$, and the loading rate of the compressive test is controlled at $2400 \pm 200 \mathrm{~N} \cdot \mathrm{s}^{-1}$, loading at a uniform rate until the specimen is damaged, and the test results are taken as the average value of each group of specimens. Thus, the flexural and compressive strength of each group of specimens is obtained.

The four-point bending test used a universal testing machine to measure the bending performance of the TRC thin-plate after exposure to high temperatures. The length of the specimen used in the test was $240 \mathrm{~mm}$, of which the pure bending section was $80 \mathrm{~mm}$, and the shear span section was $80 \mathrm{~mm}$. The displacement loading method was adopted in the test at a loading rate of $0.5 \mathrm{~mm} \cdot \mathrm{min}^{-1}$. Displacement acquisition was mDeasured using an extensometer to obtain the displacement load curve in the span of the TRC thin plate. The dimensional model used in the bending test is shown in Figure 3.

\section{RESULTS AND ANALYSIS}

Study of mechanical performance of concrete matrix after exposure to high temperatures

The average values of the high temperature compressive and flexural strengths of TRC matrix concrete with different fibers are shown in Figures 4 and 5. The results show that the compressive and flexural strengths of TRC matrix concrete with different fibers decreased with the increase of temperature. To investigate the change law of the compressive and flexural properties of TRC matrix concrete with the increase of temperature, 
the data were fitted, and the fitted curves are shown in Figures 4 and 5. The fitted curves in Figures $4 \mathrm{a}$ and 5a show that the compressive strength of TRC matrix concrete decreases with increasing temperature in a quadratic parabolic pattern, decreasing significantly until $600{ }^{\circ} \mathrm{C}$ and stabilizing after $600{ }^{\circ} \mathrm{C}$. Although aluminate cement has some high-temperature resistance, its hydration products vary with temperature [18]. From the test results, it is clear that the temperature has a significant effect on the compressive strength of concrete until the temperature rises to $400{ }^{\circ} \mathrm{C}$. This indicates that the composition and properties of the aluminate cementitious material change significantly under the effect of high temperature, while the bond between the fiber and the TRC matrix concrete deteriorates under the influence of high temperature, which together leads to a rapid decrease in its compressive and flexural strength.
After the temperature rises to $600{ }^{\circ} \mathrm{C}$, the composition of the aluminate cementing material changes less, and the compressive strength of concrete mixed with basalt fibers and steel fibers also changes less with the increase in temperature. However, the fitted curves in Figures $4 \mathrm{~b}$ and $5 \mathrm{~b}$ show that the flexural strength of TRC matrix concrete always exhibits a linear pattern of decrease with the increase of temperature, which indicates that there is always a significant effect of temperature on the flexural strength of TRC matrix concrete with different fiber. The main reason is that the fibers play a large role in the flexural properties of concrete, and both the strength of the fibers themselves and the bond strength between them and the matrix concrete will decrease with the increase in temperature. From the results in Figures 4 and 5, it can be seen that when the temperature rises to $600{ }^{\circ} \mathrm{C}$, the flexural strength continues to decrease primarily due to the change in strength and surface properties of the fiber.

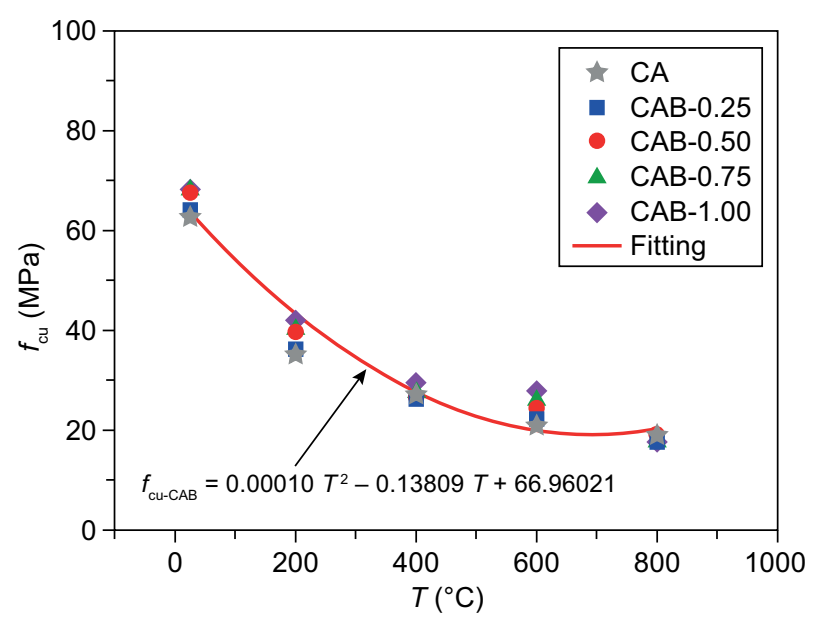

a) compressive strength

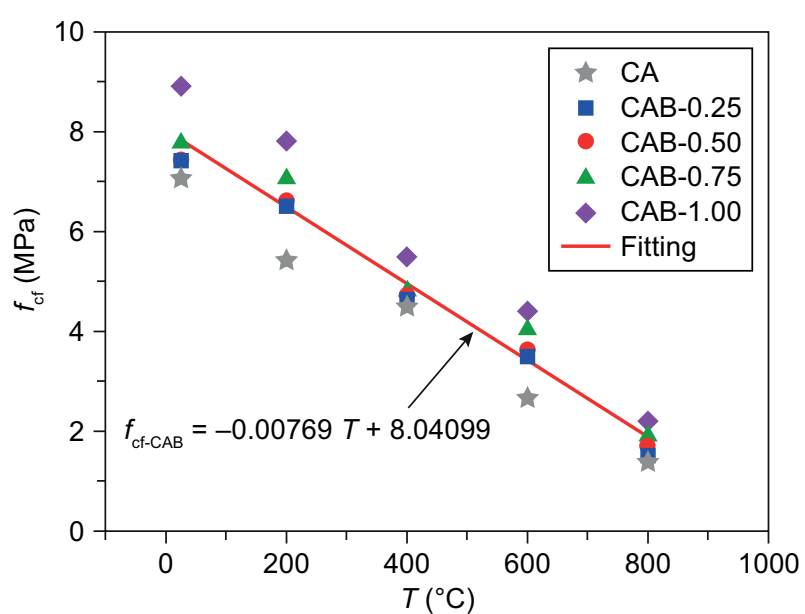

b) flexural strength

Figure 4. Change rule of compressive and flexural strength of basalt fiber concrete at different temperatures: a) compressive strength, b) flexural strength.

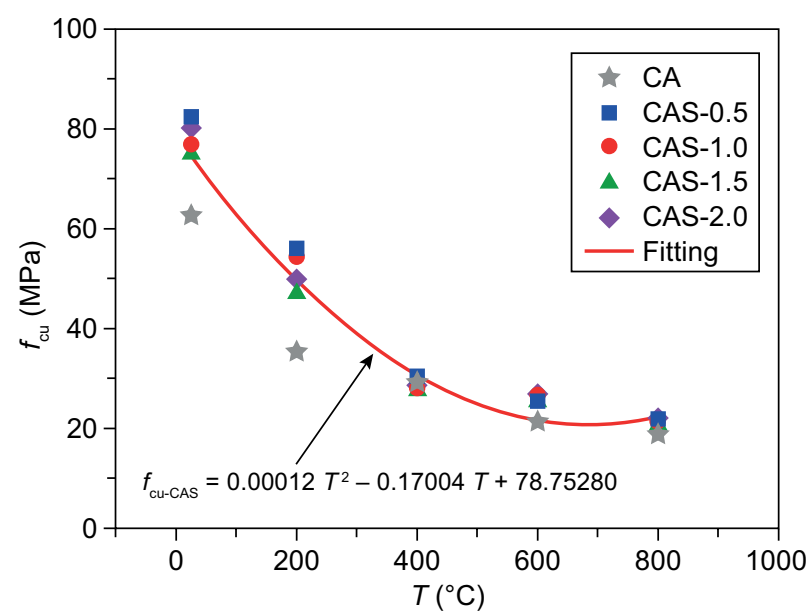

a) compressive strength

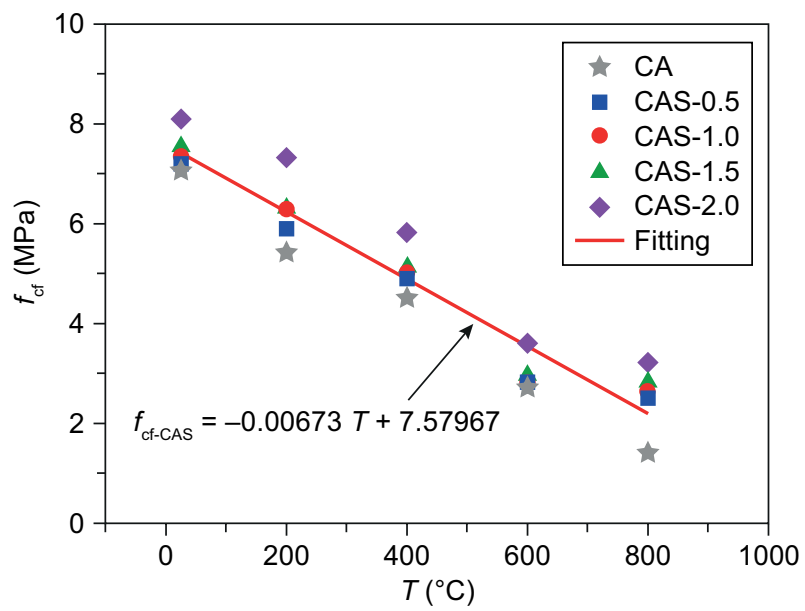

b) flexural strength

Figure 5. Change rule of compressive and flexural strength of steel fiber concrete at different temperatures: a) compressive strength, b) flexural strength. 
In addition, to investigate the effect of different fiber admixtures on the compressive and flexural strengths of TRC matrix concrete, polynomial fits were made to the mean compressive and flexural strengths of the five groups CA, CAB-0.5, CAB-1.0, CAS-1.0, and CAS-2.0, respectively, as shown in Figures 6 and 7. It can be seen that the flexural strength of concrete was increased by external fiber doping at different temperatures. As can be seen from Figure 6, the compressive strength of TRC matrix concrete with different fiber content is basically the same curve with temperature when the basalt fiber admixture is less than $1 \%$, but the fitted curve of flexural strength is obviously different, the greater the fiber admixture, the greater the flexural strength, and the more significant the decrease of flexural strength with the increase of temperature. As can be seen from Figure 7, when the steel fiber content is greater than $1 \%$, the fiber content has little effect on the compressive strength of concrete at different temperatures but has a greater effect on the flexural strength. As can be seen from Figures 6 and 7 , the change of basalt fiber admixture does not significantly affect the compressive strength values at different temperatures, but when the steel fiber content is less than $1 \%$, the steel fiber content has a greater

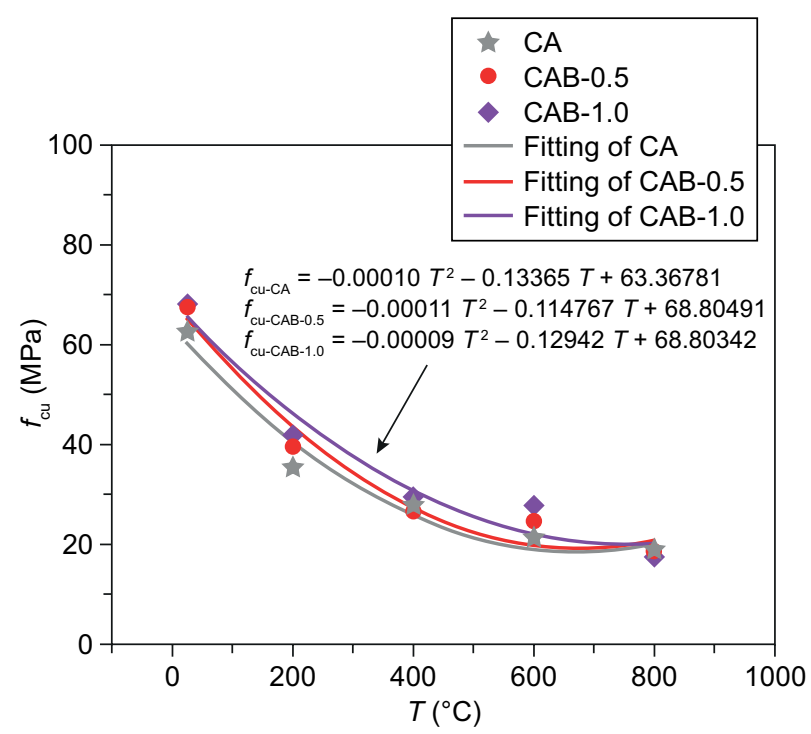

a) compressive strength

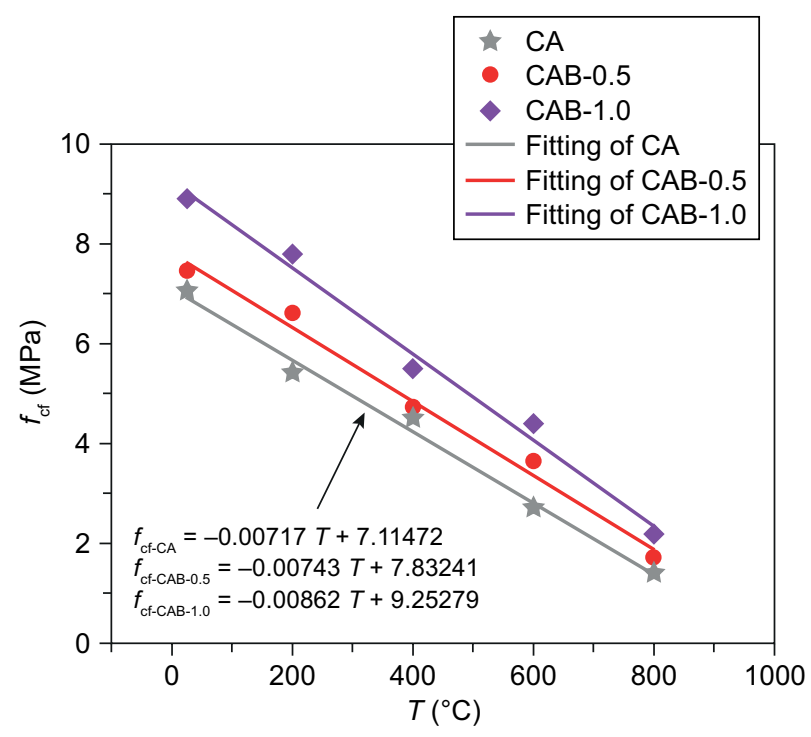

b) flexural strength

Figure 6. Change rule of compressive and flexural strength of basalt fiber concrete with different contents at different temperatures: a) compressive strength, b) flexural strength.

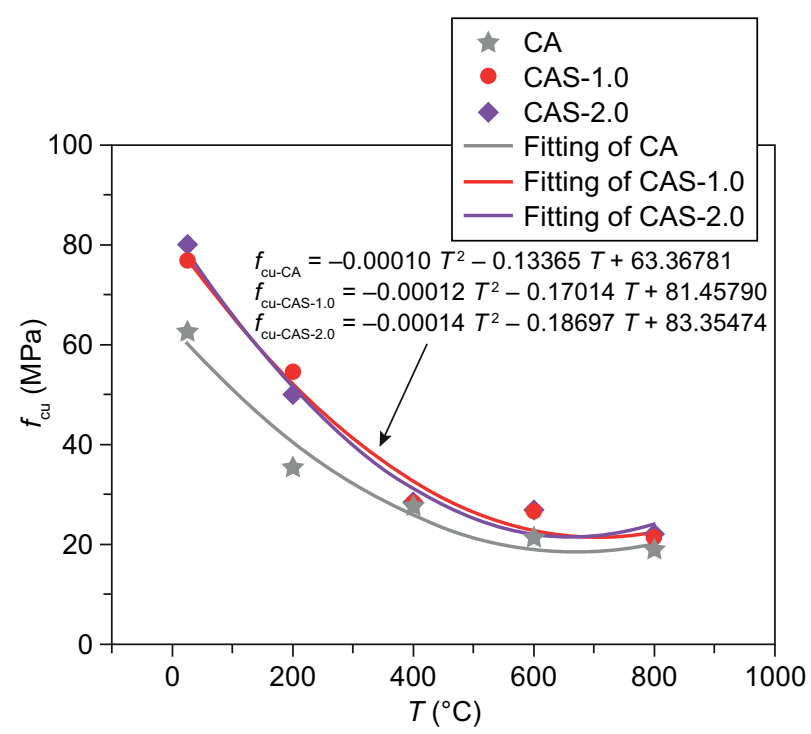

a) compressive strength

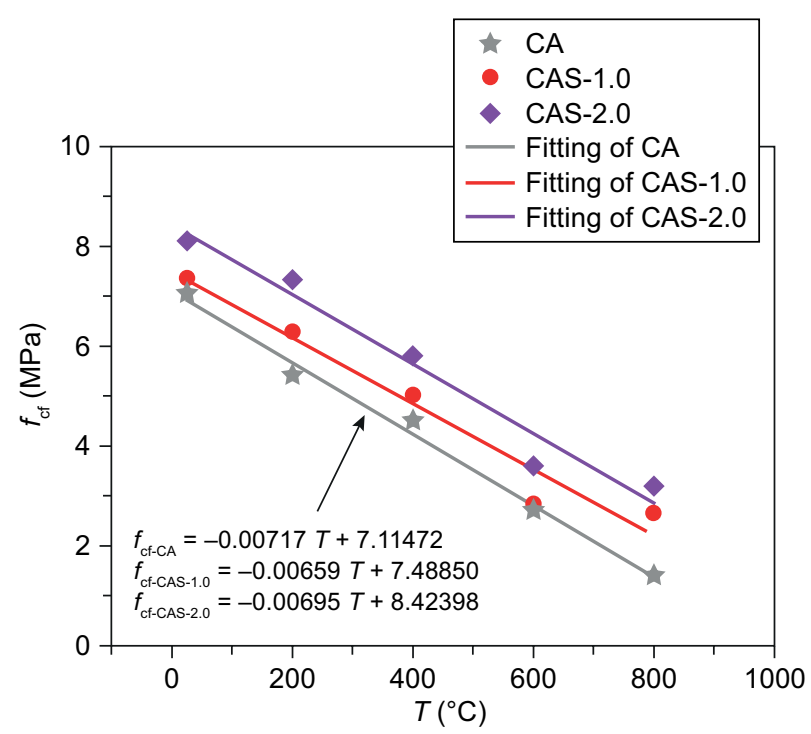

b) flexural strength

Figure 7. Change rule of compressive and flexural strength of steel fiber concrete with different contents at different temperatures: a) compressive strength, b) flexural strength. 
effect on the compressive strength values at different temperatures. When the temperature exceeds $600{ }^{\circ} \mathrm{C}$, the compressive strength of matrix concrete with different fiber admixtures is basically the same, and the fiber admixture mainly affects the flexural strength at high temperatures.

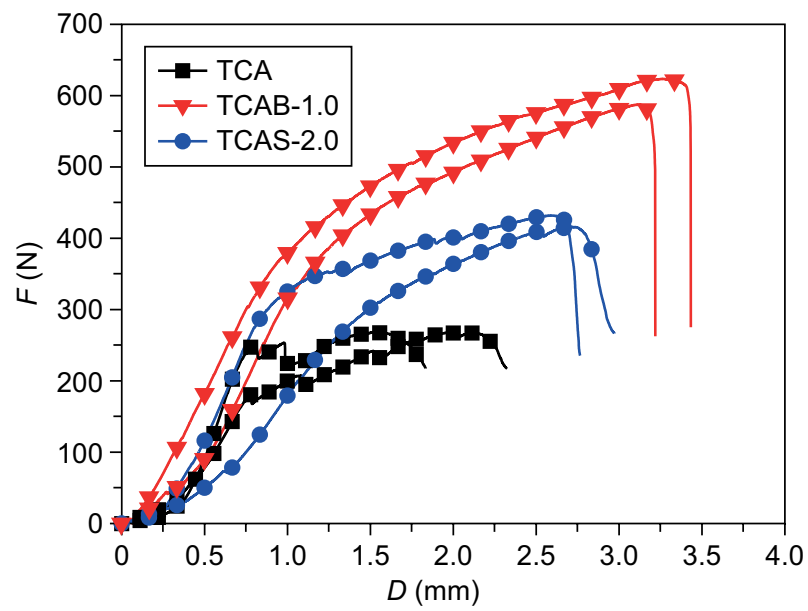

a) room temperature

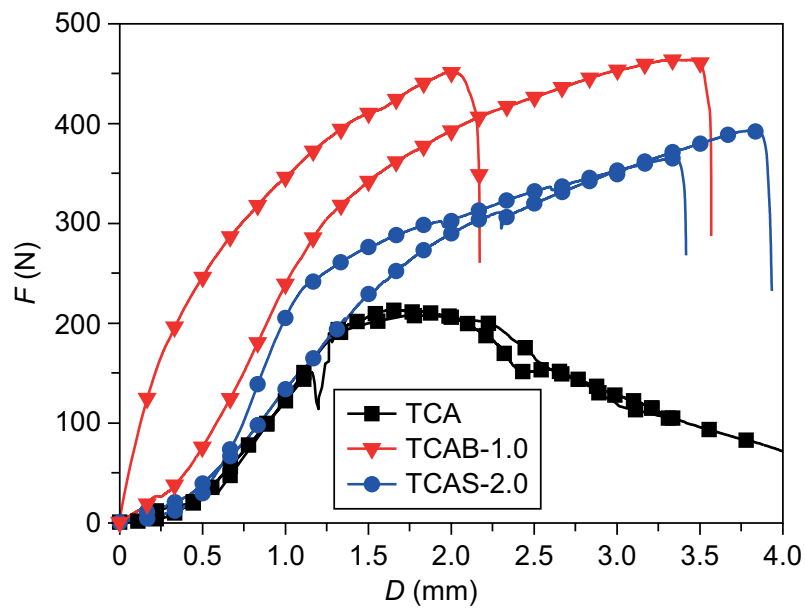

b) $200{ }^{\circ} \mathrm{C}$

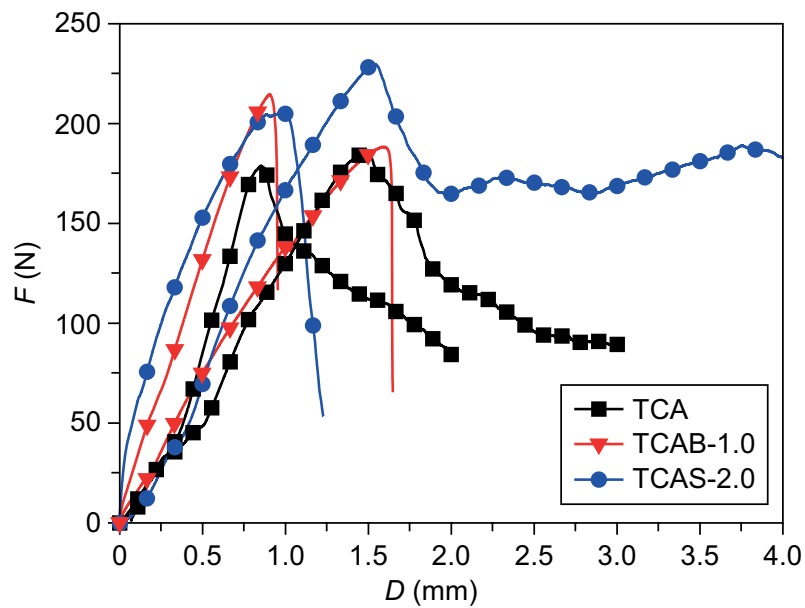

c) $400{ }^{\circ} \mathrm{C}$
Four-point bending tests of TRC thin-plate at high temperatures

After exposure to high temperatures, the bonding performance between the concrete matrix and the fibers as well as the high-temperature degradation of the fiber textile affect the mechanical performance of TRC. Thus, experimental study on the bending performance of TRC is particularly important. The four-point bending test employed TRC thin-plates prepared using specimens without fiber (TCA), that with $1 \%$ basalt fiber (TCAB1.0 ) and that with $2 \%$ steel fiber (TCAS-2.0). Two thin plates of each type of specimen were used for testing to reduce the randomness of the experiment.

Figure 8 shows the load-displacement curves of the TRC thin-plates containing high-alumina cement mixed with different fibers at different temperatures. At room temperature and at $200{ }^{\circ} \mathrm{C}$, both the short-cut basalt fiber and the short-cut steel fiber significantly improved the bending resistance of the TRC sheet. In particular, the ultimate bearing capacity of the short-cut basalt fiber reached $258 \%$ and $217.6 \%$ on average at

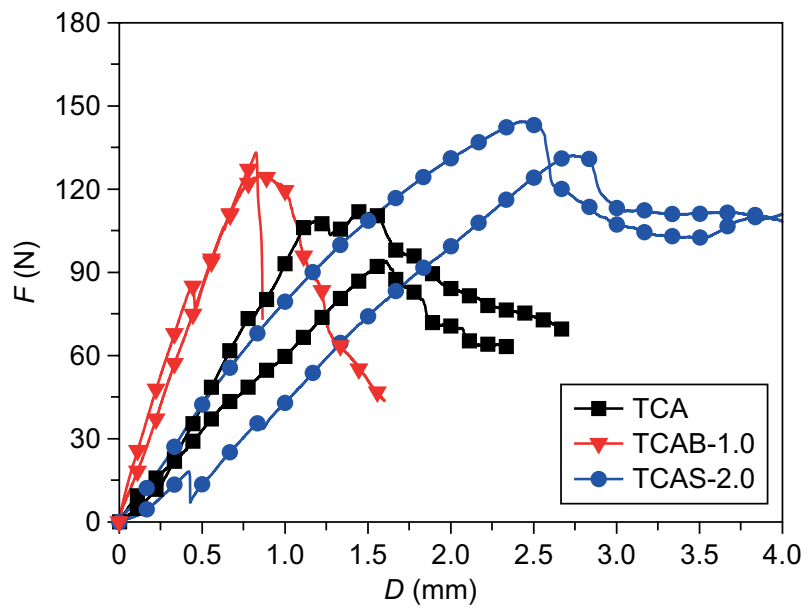

d) $600{ }^{\circ} \mathrm{C}$

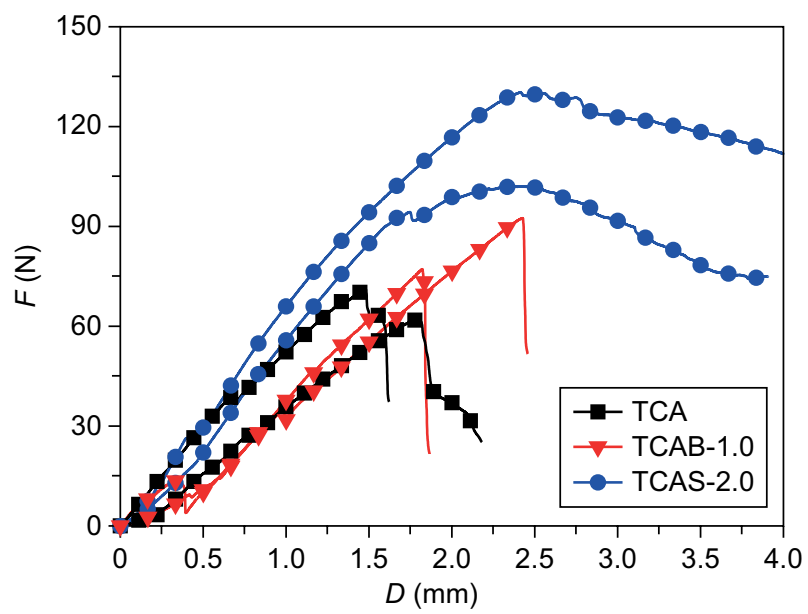

e) $800{ }^{\circ} \mathrm{C}$

Figure 8. Effects of fiber on the load-displacement curve of TRC thin-plates at different temperatures: a) room temperature, b) $200{ }^{\circ} \mathrm{C}$, c) $400{ }^{\circ} \mathrm{C}$, d) $600{ }^{\circ} \mathrm{C}$, e) $800{ }^{\circ} \mathrm{C}$. 
the two temperatures, respectively. This result indicated that short-cut fiber plays a bridging role in concrete to reduce the generation and expansion of micro-cracks. In addition, as the short-cut fiber penetrates into the basalt fiber grid, the two components jointly bear the bending action; thus, improving the ultimate bending capacity of TRC thin-plate.

At target temperatures of $400{ }^{\circ} \mathrm{C}$ and $600{ }^{\circ} \mathrm{C}$, the ultimate bearing capacity of the TRC thin-plate showed an obvious decrease, particularly that mixed with shortcut basalt fiber. When the temperature reached $800{ }^{\circ} \mathrm{C}$, the performance of the TRC thin-plate mixed with short-cut basalt fiber was not significantly improved. The main reason is that the fluidity of the concrete matrix was reduced significantly by the addition of $1 \%$ basalt fiber. Thus, the bond between the concrete matrix and the fiber textile was insufficient, which increased the internal pores. Moreover, the internal damage in the concrete matrix was more severe at higher temperatures. The TRC sheet containing short-cut steel fiber showed better bending resistance at $800{ }^{\circ} \mathrm{C}$, with a $210.2 \%$ higher ultimate load than that of the TRC sheet without fiber. Although steel fiber also degrades and damages at high temperatures, it still plays a certain role in inhibiting crack development in a concrete matrix, thus improving the ultimate bearing capacity of the TRC sheet.

Table 5 shows the ultimate load-carrying capacity with temperature for TRC sheet with different fiber.
It can be seen that the doping of short-cut basalt fibers and steel fibers can improve the ultimate load-carrying capacity of TRC sheet at high temperature. The analysis shows that when the target temperature is less than $400{ }^{\circ} \mathrm{C}, \mathrm{CAB} 1.0$ with $1 \%$ volume doping has higher ultimate bearing capacity, and the average lifting rate at room temperature can reach $225.8 \%$, but with the increase of target temperature, the lifting of short-cut basalt fibers becomes smaller. The ultimate load-bearing capacity of steel fibers at lower temperatures for TRC sheet is not as good as basalt fibers. However, the lifting rate of TRC sheet with external steel fibers is higher than that of basalt fibers at $800^{\circ} \mathrm{C}$, with an average lifting rate of $174 \%$.

\section{Composition and microstructure}

X-ray diffraction analysis (XRD; Bruker, Germany) was employed to evaluate the hydration products of high-alumina cement at different temperatures, as shown in Figure 9. The hydration products were mainly $\mathrm{AH}_{3}$, $\mathrm{C}_{3} \mathrm{AH}_{6}, \mathrm{CAH}_{10}$ and $\mathrm{C}_{2} \mathrm{AH}_{8}$ at room temperature. $\mathrm{CAH}_{10}$ and $\mathrm{C}_{2} \mathrm{AH}_{8}$ were chemically unstable, while $\mathrm{AH}_{3}$ and $\mathrm{C}_{3} \mathrm{AH}_{6}$ were relatively stable $[19,20]$. Therefore, $\mathrm{CAH}_{10}$ and $\mathrm{C}_{2} \mathrm{AH}_{8}$ changed into $\mathrm{C}_{3} \mathrm{AH}_{6}$ with the increase of age and temperature. Li also found that the initial drying period prompts the rapid conversion from metastable $\mathrm{C}_{2} \mathrm{AH}_{8}$ to stable $\mathrm{C}_{3} \mathrm{AH}_{6}[21]$. As shown by the change

Table 5. The ultimate load-carrying capacity with temperature for TRC sheet with different fibers.

\begin{tabular}{cccccc}
\hline $\begin{array}{c}\text { Temperature } \\
\left({ }^{\circ} \mathrm{C}\right)\end{array}$ & $\begin{array}{c}\text { The ultimate } \\
\text { load-carrying capacity } \\
\text { of CA }(\mathrm{N})\end{array}$ & $\begin{array}{c}\text { The ultimate } \\
\text { loa-carrying capacity } \\
\text { of CAB-1.0 }(\mathrm{N})\end{array}$ & $\begin{array}{c}\text { Average increased } \\
\text { ratio of CAB-1.0 } \\
(\%)\end{array}$ & $\begin{array}{c}\text { The ultimate } \\
\text { load-carrying capacity } \\
\text { of CAS-2.0 }(\mathrm{N})\end{array}$ & $\begin{array}{c}\text { Average increased } \\
\text { ratio of CAS-2.0 } \\
(\%)\end{array}$ \\
\hline 35 & 268.00 & 605.15 & 2.258 & 423.75 & 1.581 \\
200 & 210.15 & 457.30 & 2.176 & 378.60 & 1.801 \\
400 & 182.15 & 201.45 & 1.108 & 217.70 & 1.197 \\
600 & 103.10 & 128.89 & 1.256 & 138.20 & 1.356 \\
800 & 66.55 & 84.80 & 1.288 & 116.20 & 1.740 \\
\hline
\end{tabular}

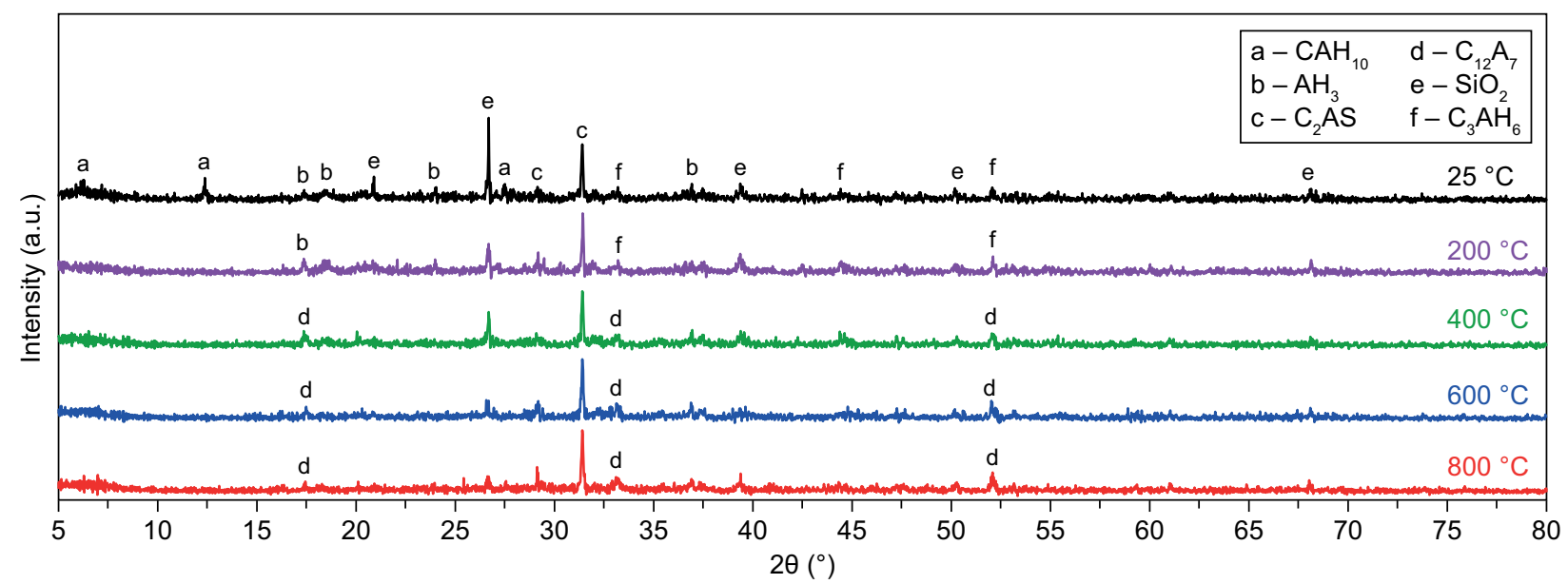

Figure 9. X-ray diffraction analysis of group CA before and after exposure to high temperatures. 
in peak intensity, the peaks indicating the presence of $\mathrm{SiO}_{2}, \mathrm{C}_{3} \mathrm{AH}_{6}$ and $\mathrm{AH}_{3}$ decreased significantly when the temperature reached $200{ }^{\circ} \mathrm{C}$. This indicates that the $\mathrm{SiO}_{2}, \mathrm{C}_{3} \mathrm{AH}_{6}$ and $\mathrm{AH}_{3}$ in the sample all undergo chemical reactions with the increase of temperature and produce new substances. After $400{ }^{\circ} \mathrm{C}, \mathrm{C}_{12} \mathrm{~A}_{7}$ appeared in the sample, which was produced by dehydration of $\mathrm{C}_{3} \mathrm{AH}_{6}$ at high temperatures [22-23], while gases were produced during the dehydration process. The gas generated loosened the dense concrete and damaged the concrete's interior; this also explains why the strength of the high-alumina cement decreased significantly before reaching $400{ }^{\circ} \mathrm{C}$. But the hydration products of high-alumina cement did not change significantly after $400{ }^{\circ} \mathrm{C}$.

Scanning electron microscopy (SEM; Quanta 250 FEG-SEM, FEI, Hillsboro, Oregon, USA) was used to analyze the micromorphology of the short-cut basalt fiber. Figure 10 shows SEM images obtained at room temperature and at a high temperature of $800{ }^{\circ} \mathrm{C}$. As shown in Figures 10a and 10b, because the short-cut basalt fiber was evenly dispersed in the concrete, new internal cross-links were formed with the basalt fiber grid

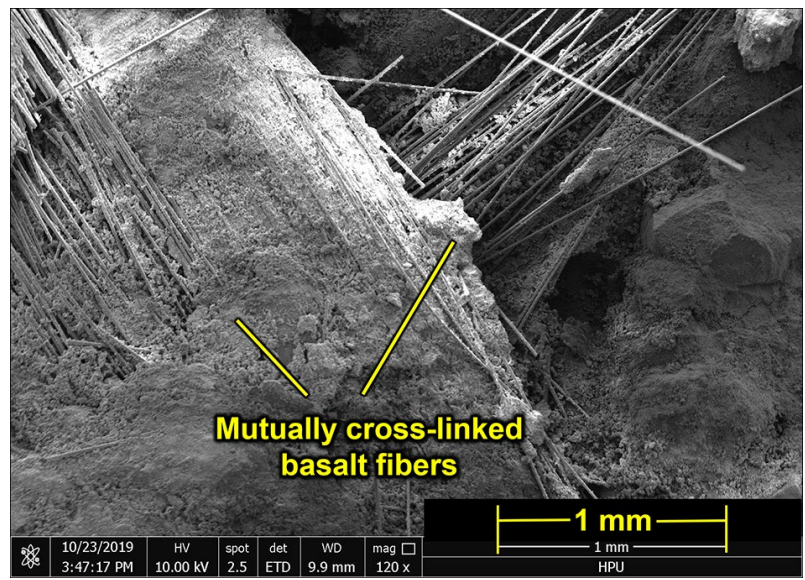

a)

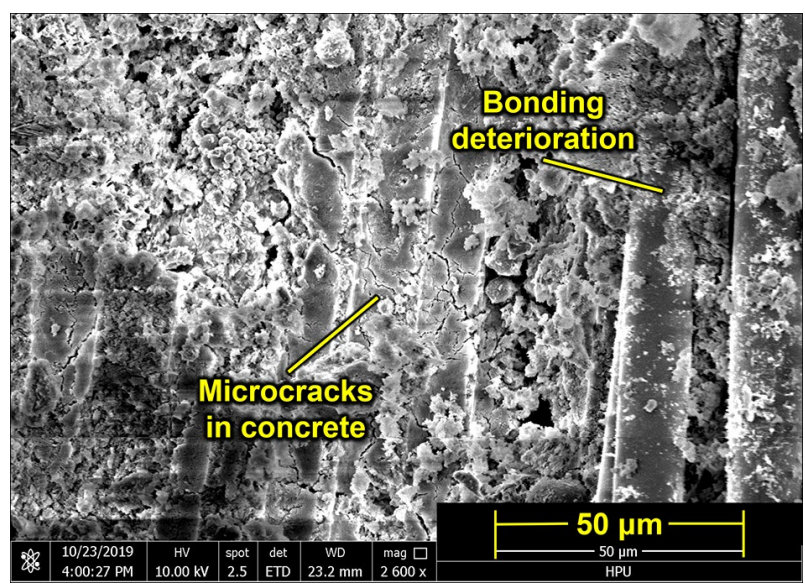

c) in the pouring process after mixing. The internal hinge acted as a secondary micro-stiffening mechanism, which enabled transmission of part of the load and controlled fracture development, thereby enhancing the bending property of the TRC sheet.

As shown in Figures 10c and 10d, when the temperature reached $800^{\circ} \mathrm{C}$, many microcracks and micropores appeared on the surface of the concrete matrix. Especially, obvious cracks appeared at the interfacial transition zone between basalt fiber and concrete matrix, and a large number of pore structures were distributed in bands near the interfacial transition zone, which led to serious deterioration of bonding. Owing to this damage to the concrete matrix and deterioration of the fiber at high temperatures, the TRC thin-plate with short-cut basalt fiber showed very limited lifting at the high temperature of $800{ }^{\circ} \mathrm{C}$.

Figure 11 shows the micromorphology of a TRC thin-plate doped with steel fibers at room temperature and at $800{ }^{\circ} \mathrm{C}$. As shown in Figure 11a, the steel fibers and the concrete matrix are tightly connected at room temperature. Moreover, Figure 11b shows that over-

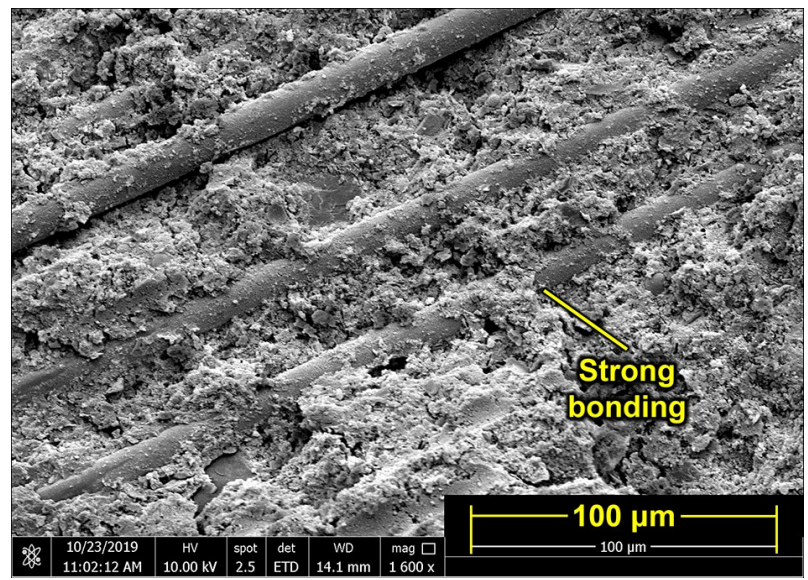

b)

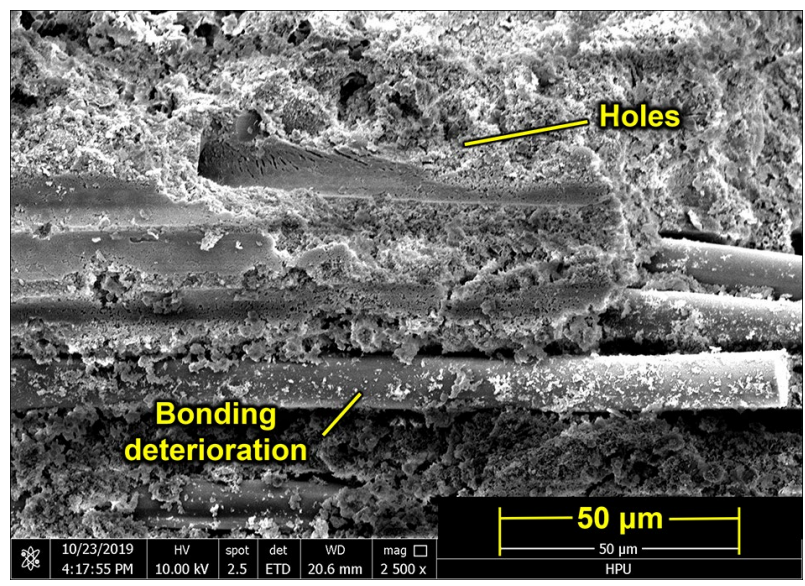

d)

Figure 10. Microstructure of short-cut basalt fibers: a) internal cross-linking of basalt fibers at room temperature, b) bond of shortcut basalt to concrete at room temperature, c) bond of short-cut basalt fiber to concrete at $800{ }^{\circ} \mathrm{C}$, d) holes left by extraction of short-cut basalt fibers at $800{ }^{\circ} \mathrm{C}$. 
lapping of the steel fiber and basalt fiber textile can form anchorage with the concrete matrix and fiber mesh, thus improving the bending performance of the TRC sheet to a certain extent.

As shown in Figure $11 \mathrm{c}$, when the temperature reaches $800^{\circ} \mathrm{C}$, the bond performance between the steel fiber and the concrete matrix decreased owing to deterioration. In addition, after the temperature increase, oxidation products composed of iron and oxygen atoms can wrap on the surface of the steel fiber. These generated oxidation products reduce the bond between the steel fiber and the concrete matrix. Figure 11d shows that the overlapping of steel fibers in the concrete matrix can also improve the bending performance of the concrete to some extent.

\section{CONCLUSIONS}

To explain the mechanical performance and failure mechanism of the TRC after high temperature, the bearing capacity testing and microscopic analysis of a TRC matrix and thin-plate were conducted. The main conclusions are summarized as follows.

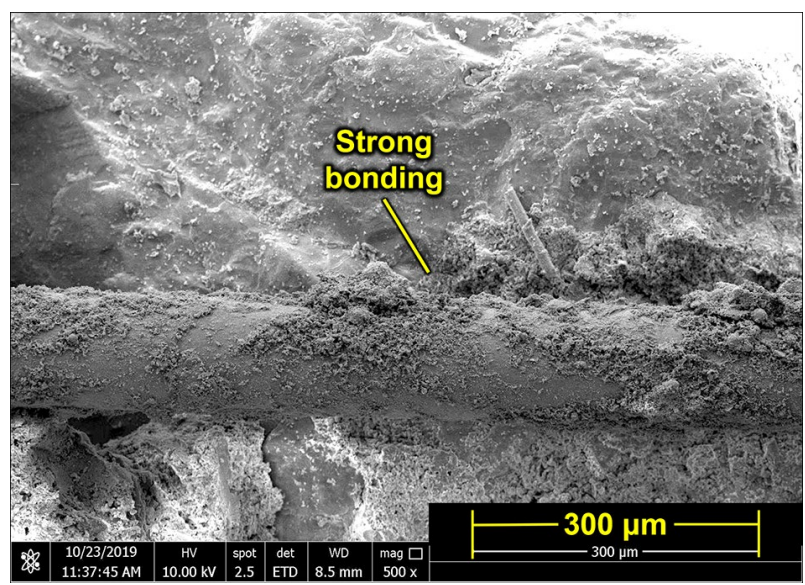

a)

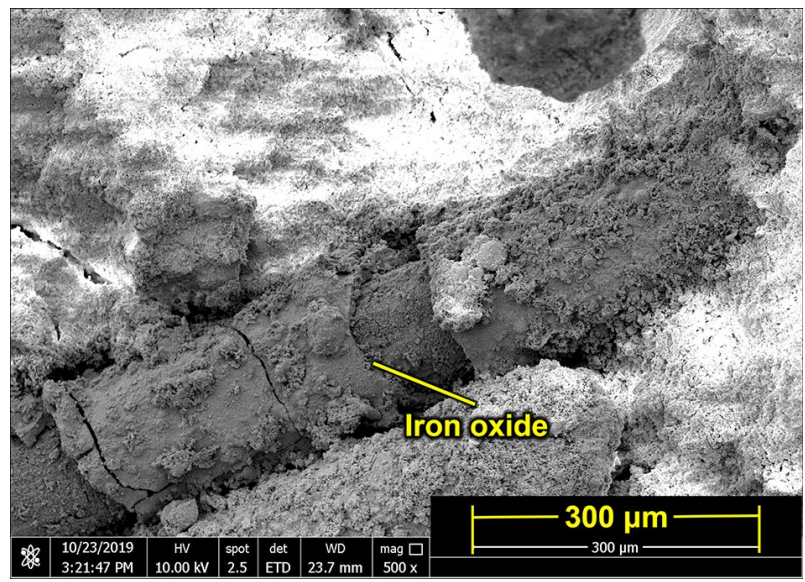

c)
- The compressive strength and flexural strength of TRC matrix concrete with different fiber decreased with the increase of temperature. Among them, the compressive strength of concrete decreases with temperature in a quadratic parabolic pattern, which decreases significantly before $600{ }^{\circ} \mathrm{C}$ and stabilizes after $600{ }^{\circ} \mathrm{C}$, while the flexural strength decreases in a linear pattern with the rise of temperature.

- Both steel fibers and basalt fibers improved the high temperature resistance of TRC matrix concrete. The change of basalt fiber admixture did not significantly affect the compressive strength values at different temperatures, but the steel fiber content had a greater effect on the compressive strength values at different temperatures when the steel fiber content was less than $1 \%$.

- The hydration products of high-alumina cement change obviously before $400{ }^{\circ} \mathrm{C}$ and stabilise after $400{ }^{\circ} \mathrm{C}$. when the temperature reached $600{ }^{\circ} \mathrm{C}$, the addition of basalt fiber resulted in obvious damage in the form of high-temperature deterioration, and the steel fiber surface oxidized with the temperature increase.

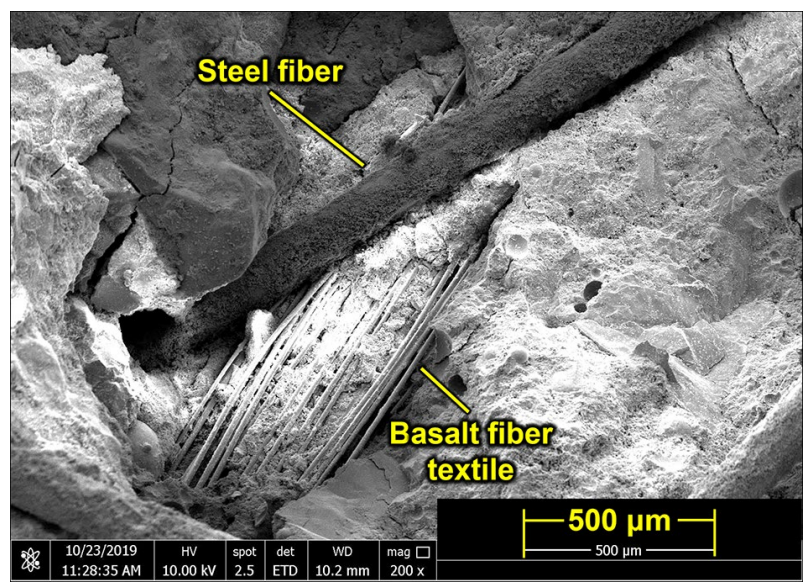

b)

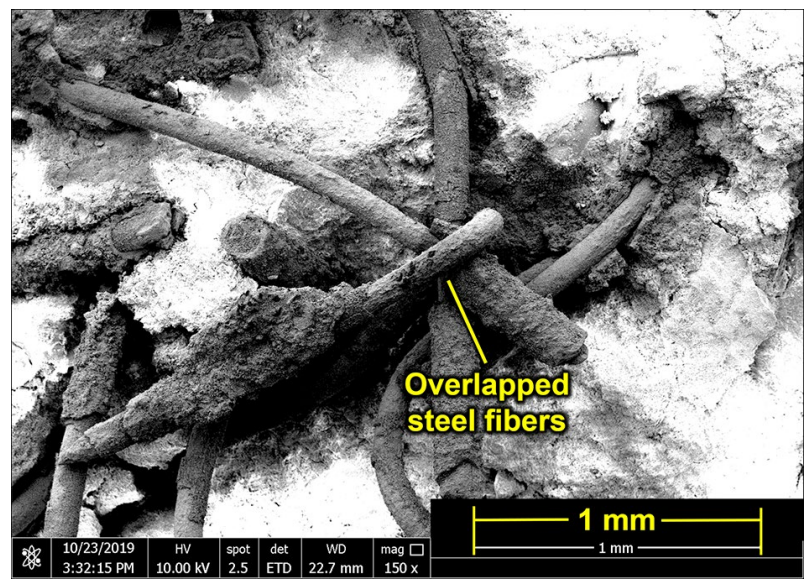

d)

Figure 11. Microstructure of short-cut steel fiber: a) bond of steel fiber to concrete at room temperature, b) steel fiber overlapped with basalt fiber textile at room temperature, c) bond of steel fiber to concrete at $800{ }^{\circ} \mathrm{C}$, d) overlapped steel fibers at $800{ }^{\circ} \mathrm{C}$.

Ceramics - Silikáty 65 (3) 263-272 (2021) 
Therefore, The decline in mechanical performance of the TRC thin-plate at high temperatures was caused by changes in the chemical composition of the concrete matrix, the degradation of the fiber itself and the damage to the bond surface.

\section{Acknowledgements}

The Youth Key Teacher Project of Henan Provincial Colleges and Universities (2017GGJS054), Financial supports from the Key Science and Technology Program of Henan Province, China (No. 202102310253), Joint Funds of the National Natural Science Foundation of China (No. U1904188), the Doctor Foundation of Henan Polytechnic University (No. B2016-67), and the Science and Technology Project of Henan Provincial Department of Transportation, China (No. 2019J-2-13) are gratefully appreciated.

\section{REFERENCES}

1. Yao Y., Silva F.A., Butler M., Mechtcherine V., Mobasher B. (2015): Tension stiffening in textile-reinforced concrete under high-speed tensile loads. Cement and Concrete Composites, 64, 49-61. doi: 10.1016/j.cemconcomp.2015. 07.009

2. Mesticou Z., Bui L., Junes A., Larbi A.S. (2017): Experimental investigation of tensile fatigue behavior of Textile-Reinforced Concrete (TRC): Effect of fatigue load and strain rate. Composite Structures, 160, 1136-1146. doi: 10. 1016/j.compstruct.2016.11.009

3. Escrig C., Gil L., Bernat-Maso E., Puigvert F. (2015): Experimental and analytical study of reinforced concrete beams shear strengthened with different types of textilereinforced mortar. Construction and Building Materials, 83, 248-260. doi: 10.1016/j.conbuildmat.2015.03.013

4. Truong G.T., Park S., Choi K. (2019): Tensile Behaviors of Lap-Spliced Carbon Fiber-Textile Reinforced Mortar Composites Exposed to High Temperature. Materials, 12, 1512. doi: $10.3390 / \mathrm{ma} 12091512$

5. Raoof S.M., Bournas D.A. (2017): Bond between TRM versus FRP Composites and Concrete at High Temperatures. Composites Part B: Engineering, 127, 150-165. doi: 10. 1016/j.compositesb.2017.05.064

6. Tetta Z.C., Bournas D.A. (2016): TRM vs FRP jacketing in shear strengthening of concrete members subjected to high temperatures. Composites PartB:Engineering, 106, 190-205. doi: 10.1016/j.compositesb.2016.09.026

7. Raoof S.M., Bournas D.A. (2017): TRM versus FRP in flexural strengthening of RC beams: Behaviour at high temperatures. Construction and Building Materials, 154, 424-437. doi: 10.1016/j.conbuildmat.2017.07.195

8. Sui Z.A., Dong K., Jiang J., Yang S., Hu K. (2020): Flexural Behavior of Fire-Damaged Prefabricated RC Hollow Slabs Strengthened with CFRP versus TRM. Materials, 13, 2556. doi: 10.3390/ma13112556

9. Li X., Bao Y., Wu L., Yan Q., Ma H., Chen G., Zhang H. (2017): Thermal and mechanical performance of high-performance fiber-reinforced cementitious composites after exposure to high temperatures. Construction and Building Materials, 157, 829-838. doi: 10.1016/j.conbuildmat.2017. 09.125

10. Al-Qadi A.N.S., Al-Zaidyeen S.M. (2014): Effect of fiber content and specimen shape on residual strength of polypropylene fiber self-compacting concrete exposed to elevated temperatures. Journal of King Saud University Science, 26, 33-39. doi: 10.1016/j.jksues.2012.12.002

11. Kelestemur O., Arici E., Yildiz S., Gokcer B. (2014): Performance evaluation of cement mortars containing marble dust and glass fiber exposed to high temperature by using Taguchi method. Construction and Building Materials, 60, 17-24. doi: 10.1016/j.conbuildmat.2014.02.061

12. Wu X., Wang S., Yang J., Zhu S. (2019): Experimental study on mechanical performance of different fibre reinforced lightweight concretes. Romanian Journal of Materials, 49, 434-442. doi: 10.1016/S1005-8885(07)60042-9

13. Tlaiji T., Vu X.H., Ferrier E., Larbi A.S. (2018): Thermomechanical behaviour and residual properties of textile reinforced concrete (TRC) subjected to elevated and high temperature loading: Experimental and comparative study. Composites Part B: Engineering, 144, 99-110. doi: 10. 1016/j.compositesb.2018.02.022

14. Homoro O., Vu X.H., Ferrier E. (2018): Experimental and analytical study of the thermo-mechanical behaviour of textile-reinforced concrete (TRC) at elevated temperatures: Role of discontinuous short glass fibers. Construction and Building Materials, 190, 645-663. doi: 10.1016/j.conbuildmat.2018.09.142

15. Salomão R., Kawamura M.A., Emilio A.B.V., Sakihama J., Segadães A.M. (2021): Calcium aluminate cement in castable alumina: From hydrate bonding to the in situ formation of calcium hexaluminate. Ceramics International, 47, 15082-15093. doi: 10.1016/J.CERAMINT.2021.02.066

16. Wang Y., Li X., Zhu B., Chen P. (2016): Microstructure evolution during the heating process and its effect on the elastic properties of CAC-bonded alumina castables. Ceramics International, 42, 11355-11362. doi: 10.1016/j.ceramint.2016.04.058

17. Xu S., Shen L., Wang J. (2016): The high-temperature resistance performance of TRC thin-plates with different cementitious materials: Experimental study. Construction and Building Materials, 115, 506-519. doi: 10.1016/j. conbuildmat.2016.04.070

18. Khaliq W., Khan H.A. (2015): High temperature material properties of calcium aluminate cement concrete. Construction and Building Materials, 94, 475-487. doi: 10.1016/j. conbuildmat.2015.07.023

19. Cheng X., Dong Q., Ma Y., Zhang C., Gao X., Yu Y., Wen Z., Zhang C., Guo X. (2019): Mechanical and thermal properties of aluminate cement paste with blast furnace slag at high temperatures. Construction and Building Materials, 228, 116747. doi: 10.1016/j.conbuildmat.2019.116747

20. Idrees M., Ekincioglu O., Sonyal M.S. (2021): Hydration behavior of calcium aluminate cement mortars with mineral admixtures at different curing temperatures. Construction and Building Materials, 285, 122839. doi: 10.1016/j.conbuildmat.2021.122839

21. Li N., Wang X., Mu Y., Zhang R., Zhu L., Ye G. (2021): Mechanical property and phase evolution of the hydrates of CAC-bonded alumina castables during drying at $110^{\circ} \mathrm{C}$. Construction and Building Materials, 266, 120962. doi: 10.1016/j.conbuildmat.2020.120962

22. Lee N.K., Koh K.T., Park S.H., Ryu G.S. (2017): Microstructural investigation of calcium aluminate cement-based ultra-high performance concrete (UHPC) exposed to high temperatures. Cement and Concrete Research, 102, 109-118. doi: 10.1016/j.cemconres.2017.09.004

23. Antonovič V., Kerienė J., Boris R., Aleknevičius M. (2013) The effect of temperature on the formation of the hydrated calcium aluminate cement structure. Procedia Engineering, 57, 99-106. doi: 10.1016/j.proeng.2013.04.015 